\title{
Flame propagation over a methane hydrate with surface temperature variation in a natural convective flow field
}

\author{
Tomoki YOSHIOKA*, Masanori SUEMITSU*, Takeshi YOKOMORI*, Ryo OHMURA* \\ and Toshihisa UEDA* \\ ${ }^{*}$ Department of Mechanical Engineering, Keio University \\ 3-14-1 Hiyoshi, Kohoku-ku, Yokohama, Kanagawa 223-8522, Japan \\ E-mail: ueda@mech.keio.ac.jp
}

Received 6 July 2015

\begin{abstract}
Flame propagation over methane hydrate in an axisymmetric geometry with a non-uniform initial surface temperature profile is investigated experimentally. The methane hydrate in a container with 100 mm diameter and $10 \mathrm{~mm}$ depth is ignited at the center of the hydrate surface by a pilot flame. The ignition temperature, $T_{\mathrm{s}, \mathrm{ig}}$, which is measured by a thermocouple $1 \mathrm{~mm}$ beneath the hydrate surface at the center of the hydrate, is varied from $173 \mathrm{~K}$ to $253 \mathrm{~K}$. When $T_{\mathrm{s}, \mathrm{ig}},=173 \mathrm{~K}$, which is lower than the nominal equilibrium temperature of methane hydrate $(193 \mathrm{~K})$, the flame propagates axisymmetrically at a low velocity of around $10 \mathrm{~mm} / \mathrm{s}$. As the flame propagates, the heat from the flame front dissociates the hydrate. As $T_{\mathrm{s}, \mathrm{ig}}$ exceeds the nominal equilibrium temperature $\left(T_{\mathrm{s}, \mathrm{ig}}=193\right.$ and $\left.213 \mathrm{~K}\right)$, the flame propagates at a high velocity of around $1000 \mathrm{~mm} / \mathrm{s}$. The hydrate surface dissociates and a methane-air mixture within the flammability limit is formed before ignition, and the flame propagates in the mixture after ignition. At $T_{\mathrm{s}, \mathrm{ig}}=233 \mathrm{~K}$, the flame propagates fast at around $1000 \mathrm{~mm} / \mathrm{s}$ until the flame front reaches the radial distance $\mathrm{r}$ about $40 \mathrm{~mm}$ and the propagation velocity drops to around 10 $\mathrm{mm} / \mathrm{s}$ and propagates to $50 \mathrm{~mm}$, where it reaches the container wall. The methane hydrate dissociates and methane is ejected into the air up to $r=40 \mathrm{~mm}$. However, in the region between $r=40$ and $50 \mathrm{~mm}$, the surface temperature is around $253 \mathrm{~K}$ where the hydrate is under the self-preservation conditions. At $T_{\mathrm{s} \text {,ig }}$ of $253 \mathrm{~K}$, the initial temperature is in the self-preservation region, and then the flame propagation velocity is as low as that at $T_{\mathrm{s}, \mathrm{ig}}=173 \mathrm{~K}$
\end{abstract}

Key words : Combustion, Methane hydrate, Flame propagation, Natural convection, Buoyancy

\section{Introduction}

Methane hydrate is a clathrate hydrate that contains methane as a guest material. A huge amount of methane hydrate is contained in marine sediments throughout the world, and it is expected to be used as a new energy source (Klauda and Sandler 2005). In addition, methane hydrate may be an alternative to liquefied natural gas (LNG) for transporting and storing natural gas. The storage conditions for methane hydrate (around $253 \mathrm{~K}$ at atmospheric pressure under selfpreservation conditions) are less extreme than those for LNG (boiling point of $111 \mathrm{~K}$ at atmospheric pressure) (Gudmundsson et al. 1996; Javanmardi et al. 1996; Kim et al. 2004; Mori 2003).

The combustion characteristics of methane hydrate have been studied. A flame spreading in a laminar boundary layer over a combustible hydrate against an airflow was investigated for tetrahydrofuran hydrate (Iwata and Ueda 2002), and for methane hydrate numerically (Kitamura et al. 2002) and experimentally (Nakamura et al. 2009; Maruyama et al. 2013). Two types of flame propagation were observed, depending on the surface temperature of the methane hydrate. When the surface temperature was below the dissociation temperature, the flame propagates slowly, at a speed of several millimeters per second. The hydrate in front of the flame front was dissociated by the heat from the flame front. When the surface temperature exceeded the dissociation temperature, the flame propagates rapidly, at a speed of around thousand millimeters per second, because a methane-air mixture formed over the methane hydrate on the upstream side of the flame front and the flame propagated in the mixture. When the surface temperature increased to around $253 \mathrm{~K}$, the 
flame propagation speed decreased drastically to several millimeters per second, similar to the case where the surface temperature was below its dissociation temperature. This is due to the self-preservation effect (Stern et al. 2001). These results revealed that the surface temperature of the hydrate plays an important role in flame propagation over methane hydrates. The combustion characteristics of propane hydrates in porous media has also been investigated experimentally. The accumulation of hydrate-dissociated water over the hydrate surface prevented the heat transfer from the flame to the hydrate and the gas ejection into the combustion zone (Chen et al. 2015).

We have elucidated the characteristics of combustion, particularly flame propagation under forced convection conditions (Iwata and Ueda 2002; Kitamura et al. 2002; Nakamura et al. 2009; Maruyama et al. 2013). However, flame propagation under natural convection conditions has not been discussed yet. In a large-scale container accident, the buoyancy is expected to affect the flow field around the flame in a natural convective flow field. In addition, the surface temperature is not uniform and the surface temperature near the container wall would be higher than that at the center because of the heat transfer from the wall. In this study, we investigate flame propagation over a methane hydrate in a container with non-adiabatic walls in a natural convective flow field, where buoyancy should affect the flame.

\section{Experimental apparatus and procedure}

Figure 1 shows the experimental apparatus, which consists of a methane hydrate container, an ignition burner, and a measurement system. An overview of the apparatus is shown in Figure 1(a). The calcium silicate container has an inner diameter of $100 \mathrm{~mm}$ and a depth of $10 \mathrm{~mm}$ (Figure 1(b)), and it is surrounded by a doughnut-shaped outer wall made by calcium silicate to maintain the axisymmetric geometry. The outer wall is used to set the appropriate heat transfer from the wall, in other words, the methane hydrate is heated in the horizontal direction through the outer wall as well as in the vertical direction through the hydrate surface from the top and through the outer wall from the bottom. Methane hydrate powder (about $30 \mathrm{~g}$ ) with a particle size of less than $0.5 \mathrm{~mm}$ is placed in a container flush with the surface of the outer wall. The container is cooled in a liquid nitrogen vapor condition until the hydrate is set in the container in order not to dissociate methane hydrate powder before it is placed. The top of the hydrate surface is ignited along the centerline with a small flame about $3 \mathrm{~mm}$ diameter formed on the ignition burner. The coordinate system is defined as shown in Figure 1(c). The temperature in the hydrate is measured by K-type thermocouples placed below the surface as shown in Figure 1(c). Three thermocouples are located $1 \mathrm{~mm}$ below the hydrate surface to measure the surface temperature, and two are set $3 \mathrm{~mm}$ below the hydrate surface to measure the internal temperature of the hydrate. The flame motion is recorded by a digital high-speed video camera.

The decrease in the mass of the methane hydrate in the container is measured with the surface temperature $T_{s}$ by setting the container on a digital scale in the closed cage with a gas inlet and outlet $(700 \mathrm{~mm} \times 500 \mathrm{~mm} \times 450 \mathrm{~mm}) \mathrm{set}$ on a horizontal table. Before the measurements, nitrogen gas was injected from the inlet at a flow rate of $30 \mathrm{~L} / \mathrm{min}$ for about 20 min to purge air containing moisture from the outlet. The cage temperature and humidity were measured with a thermometer and hydrometer, respectively. The decrease in the mass of the container with time is recorded, and the methane ejection velocity is calculated by dividing the decrease in the methane hydrate mass by time and the area of the opening of the container. Thus, the calculated methane gas ejection velocity is surface averaged, although the local ejection velocity should vary as a function of the surface temperature. The experiments are conducted under the conditions of $1 \mathrm{~atm}$, room temperature around $293 \mathrm{~K}$.

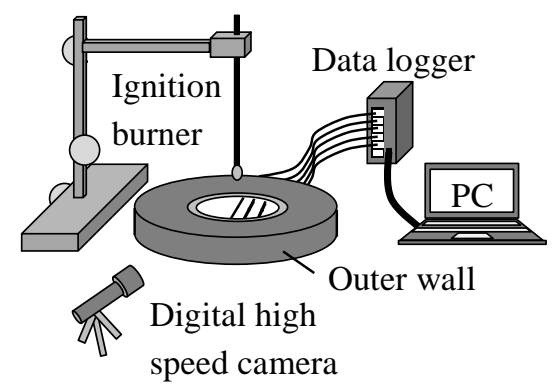

(a)

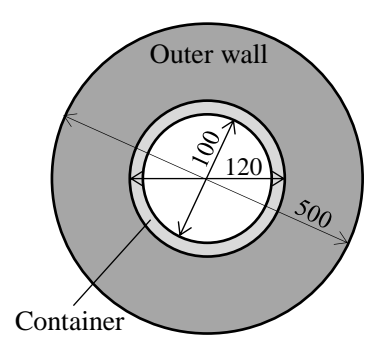

(b)

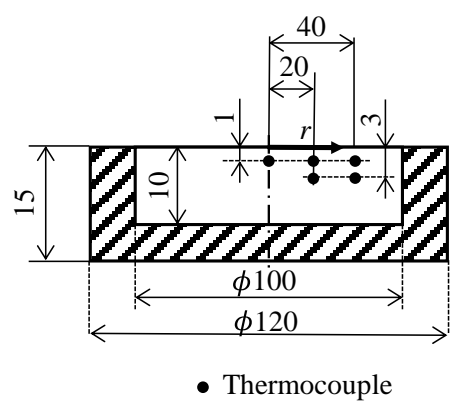

(c)

Figure 1 Schematic of the experimental apparatus: (a) overview of the apparatus; (b) top view of the methane hydrate container; and (c) side view of the methane hydrate container 


\section{Results and Discussion}

\subsection{Methane gas ejection velocity from the methane hydrate surface}

To discuss the variation in the flame propagation velocity, the relationship between the methane gas ejection velocity, $v_{e}$, and the surface temperature, $T_{s}$, was estimated experimentally. $T_{s}$ is the temperature measured by a thermocouple 1 mm beneath from the surface of methane hydrate at the center. The initial surface temperature profile at each $T_{s}$ is shown in Figure 2. The minimum initial surface temperature was at the centerline, and it gradually increased with the radial distance from the centerline, $r$, because of the heat transfer through the container wall. Figure 3(a) shows the variation in the methane hydrate mass and $T_{s}$ with time at initial condition was $170 \mathrm{~K}$. $T_{s}$ increased and the methane hydrate mass decreased. The relationship between $T_{s}$ and the methane gas ejection velocity shown in Figure 3(b) was obtained from Figure 3(a). The methane gas ejection velocity gradually increased with $T_{s}$ from $T_{s}=173 \mathrm{~K}$. It means that methane gas ejection was observed even when $T_{s}$ was lower than the dissociation temperature. This is because the surface temperature increased with $r$ from the centerline as shown in Figure 2. The methane gas ejection velocity decreased after it reached a maximum around $213 \mathrm{~K}$. At $T_{s}=233 \mathrm{~K}$, the temperature at $r=40 \mathrm{~mm}$ was in the self-preservation condition, which results in the decrease in the methane gas injection velocity. At $T_{s}=253 \mathrm{~K}$, most of the hydrate surface area was under self-preservation conditions, which resulted in almost zero methane ejection. Figure 3(b) also shows the methane gas ejection velocity for a rectangular container (Maruyama et al. 2013). In this case, $T_{s}$ was measured 1 mm beneath from the hydrate surface at the center of the rectangular surface of hydrate. The velocity variation with $T_{s}$ shows similar trend quantitatively although the shape of methane hydrate surface is different, one is axisymmetric and the other rectangular. The velocity showed similar variation with $T_{s}$, although the surface temperature at maximum $v_{e}$ was not the same because the container was rectangular rather than axisymmetric. The difference in container shape altered the surface temperature profile, resulting in the qualitative difference of methane gas ejection velocity at the same $T_{s}$.

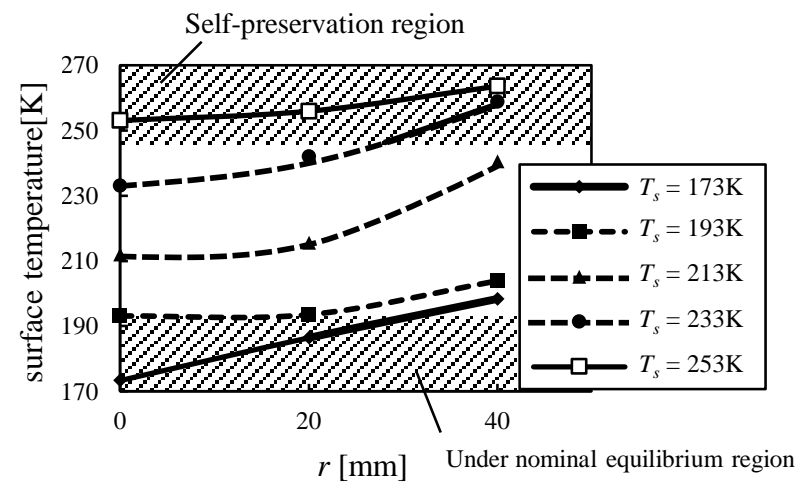

Figure 2 Profile of the initial surface temperature of the methane hydrate

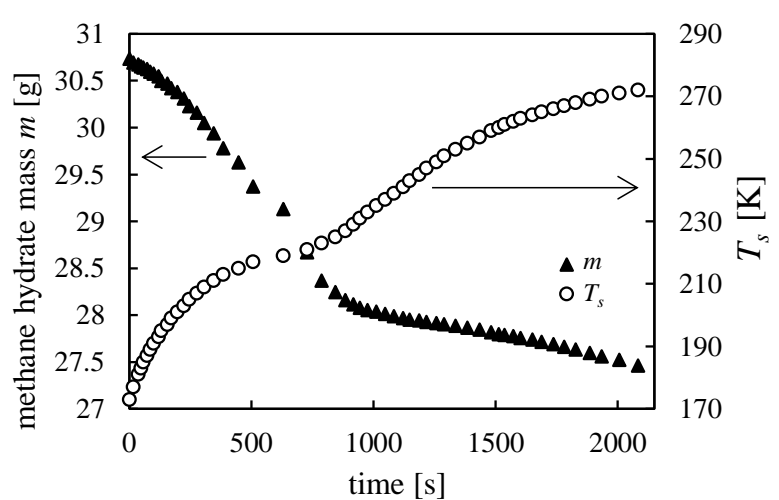

(a)

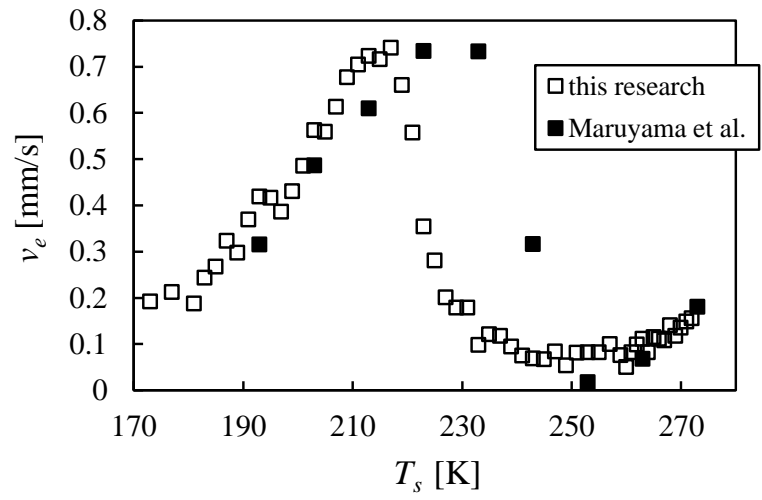

(b)

Figure 3 Variations in the methane hydrate properties with time: (a) variation of methane hydrate mass, $m$, and surface temperature, $T_{s}$, during methane hydrate dissociation; and (b) variation of methane gas ejection velocity, $v_{e}$, during methane hydrate dissociation in this work and in the rectangular container reported by Maruyama et al. (2013) 


\subsection{Flame propagation}

Figure 4 shows snapshots of the flame shape over the methane hydrate. The time at the ignition along the centerline of the methane hydrate surface is defined as $0 \mathrm{~s}$. Two types of flame propagation were observed: low-speed flame propagation (Fig. 4(a)) and high-speed flame propagation (Fig. 4(b)). These types of flame propagation were related to the centerline surface temperature at the ignition $T_{s, i g}$. Figure 5 (a) shows the variation in the flame location with time as a function of $T_{s, i g}$. Flame propagation velocity calculated by the variation in the flame front location with time is shown in Fig. 5(b). When $T_{s, i g}=173 \mathrm{~K}$, the flame location linearly increased with time and the propagation velocity was slow at about $10 \mathrm{~mm} / \mathrm{s}$. When $T_{s, i g}=193$ and $213 \mathrm{~K}$, the flame propagated fast at around $1000 \mathrm{~mm} / \mathrm{s}$. When $T_{s, i g}=233 \mathrm{~K}$, the flame started to propagate with a high propagation velocity, similar to those at $T_{s, i g}=193$ and $213 \mathrm{~K}$. However, when the flame reached around $r=40 \mathrm{~mm}$, the flame propagation velocity decreased dramatically and was closer to that at $T_{s, i g}=$ $173 \mathrm{~K}$. At $T_{s, i g}=253 \mathrm{~K}$, the propagation velocity was slow at about $10 \mathrm{~mm} / \mathrm{s}$, which was similar to that at $T_{s, i g}=173 \mathrm{~K}$. The high-speed flame propagation velocity was about 100 times faster than that of the low-speed flame propagation. This result agreed with the results for flame propagation in a forced convective laminar boundary layer (Maruyama et al. 2013) as shown in Fig. 5(b).

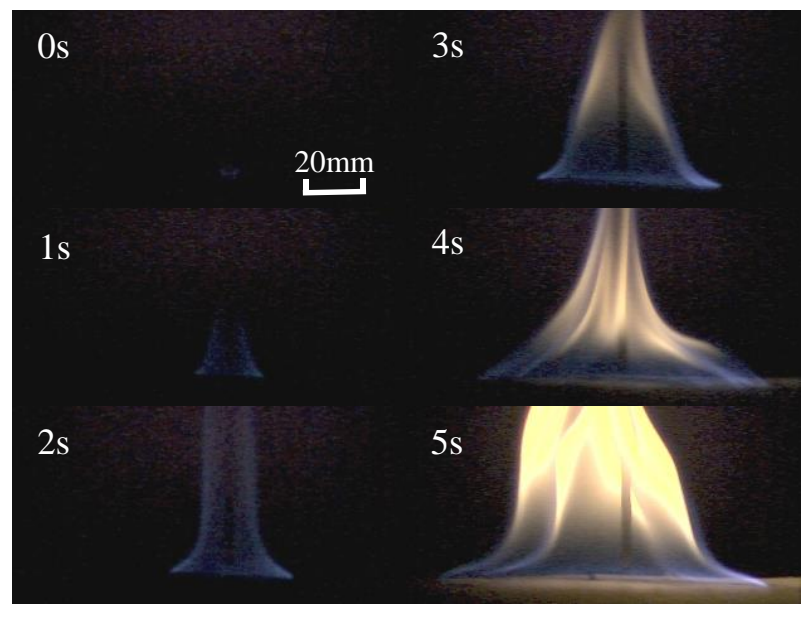

(a)

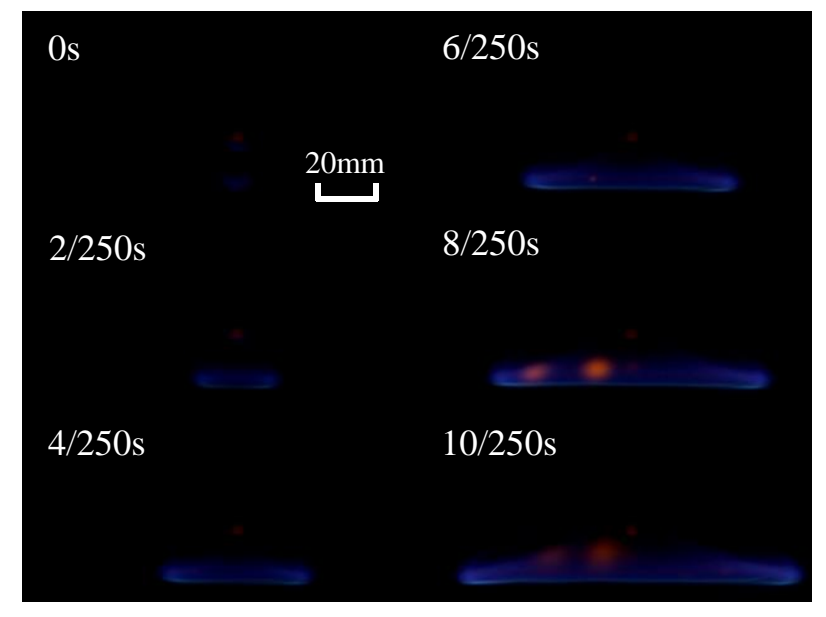

(b)

Figure 4 Behavior of flame propagation over the methane hydrate: (a) low-speed flame propagation $\left(T_{s, i g}=173 \mathrm{~K}\right)$; and (b) high-speed flame propagation $\left(T_{s, i g}=193 \mathrm{~K}\right)$

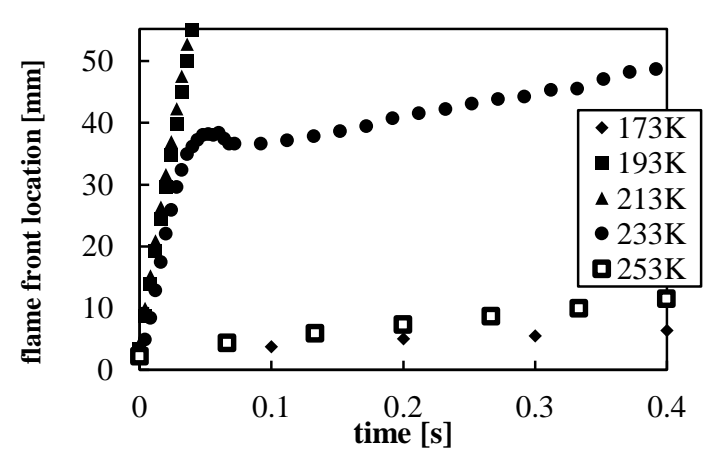

(a)

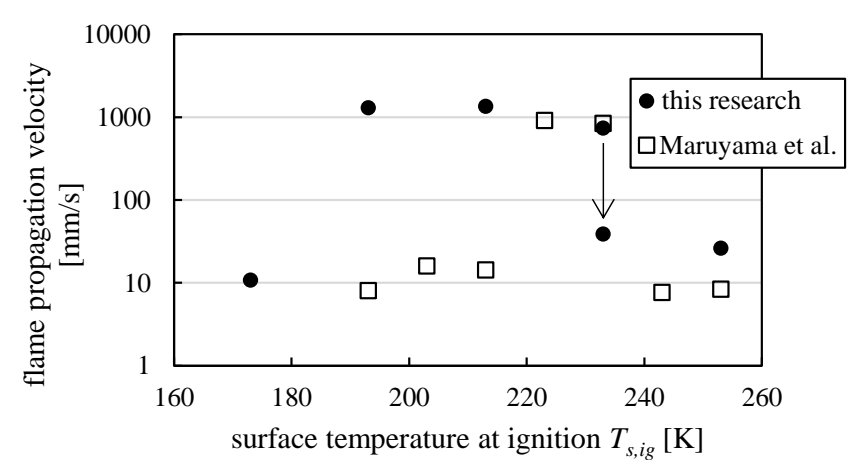

(b)

Figure 5 Variation of the flame front with time and flame propagation velocity: (a) variation of the flame front location with time; and (b) variation of flame propagation velocity with the surface temperature at ignition 


\subsection{Temperature variation}

Figure 6 shows the variation in the methane hydrate surface temperature during flame propagation at $r=0,20$, and $40 \mathrm{~mm}$. For $T_{\mathrm{s}, \mathrm{ig}}=173 \mathrm{~K}$ (Figure $\left.6(\mathrm{a})\right)$, the surface temperature at $(y, r)=(-1,0)$ and $(-1,20)$ was lower than the nominal equilibrium temperature $(193 \mathrm{~K}$ at $0.1 \mathrm{MPa})$ and similar at $(y, r)=(-1,40)$. The surface temperature at $r=0 \mathrm{~mm}$ remained at $173 \mathrm{~K}$ after the flame was ignited. This indicates that the dissociation of a thin layer of the methane hydrate, less than $1 \mathrm{~mm}$ deep, occurs at ignition. In the present study, natural convection dominated the flow field, and then the flame surface moved upward after the ignition. The temperature inside the hydrate was below the nominal equilibrium temperature, as seen at $(y, r)=(-3,20)$, and then the temperature at $(y, r)=(-1,0)$ changed slowly causing slow dissociation $1 \mathrm{~mm}$ below the hydrate surface. At $r=20 \mathrm{~mm}$, the surface temperature started to increase after the flame front arrived, whereas at $r=40 \mathrm{~mm}$, the surface temperature started to increase just before. This suggests that the hot gas in front of the flame front moved slightly faster than the flame front and heated the hydrate surface beyond the flame front. At $T_{\mathrm{s}, \mathrm{ig}}=213 \mathrm{~K}$ (Figure 6(b)), the surface temperature was higher than the nominal equilibrium temperature at all three positions, $r=0,20$, and $40 \mathrm{~mm}$. Therefore, the dissociation started over the whole hydrate surface forming the methane-air mixture over the hydrate before the flame is ignited, and the flame propagated in the mixture. At $T_{\mathrm{s}, \mathrm{ig}}=233$ $\mathrm{K}$ (Figure 6(c)), the surface temperature of each location was constant during the flame propagation. Interestingly, the surface temperature at $r=40 \mathrm{~mm}$ was about $253 \mathrm{~K}$, which was within the self-preservation temperature range $(243 \mathrm{~K}<$ $T_{s}<273 \mathrm{~K}$ ). Thus, the hydrate around $r=40 \mathrm{~mm}$ was under self-preservation conditions, and less methane gas was ejected from the hydrate. As a result, the propagation velocity dropped drastically around $r=40 \mathrm{~mm}$. For $T_{\mathrm{s}, \mathrm{ig}}=253 \mathrm{~K}$ (Figure 6(d)), the initial temperatures at $r=0,20$, and $40 \mathrm{~mm}$ were under self-preservation conditions. The temperature of each location started to increase as the flame approached. The temperature at $r=40 \mathrm{~mm}$ increased to $273 \mathrm{~K}$, and the ice started to melt.

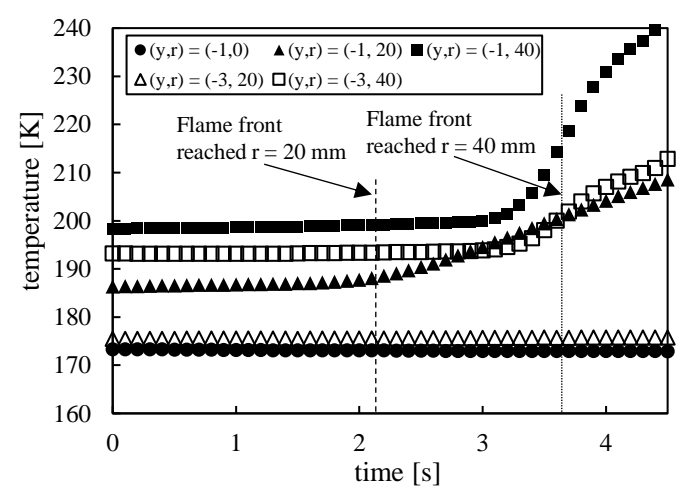

(a)

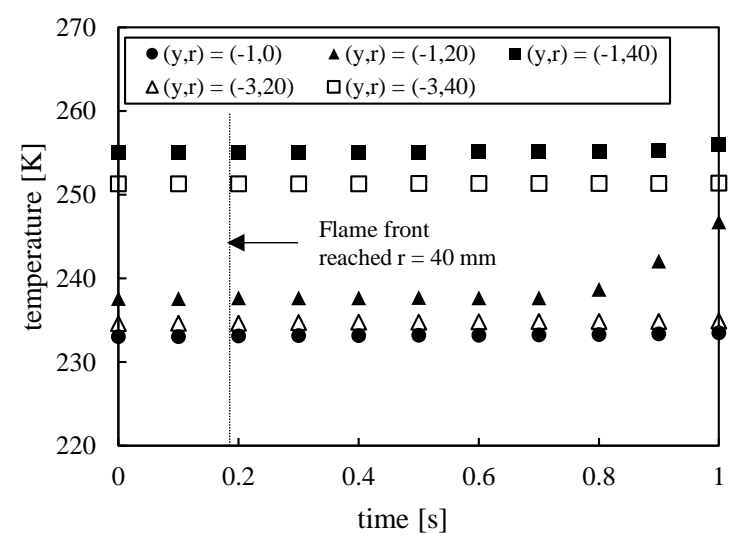

(c)

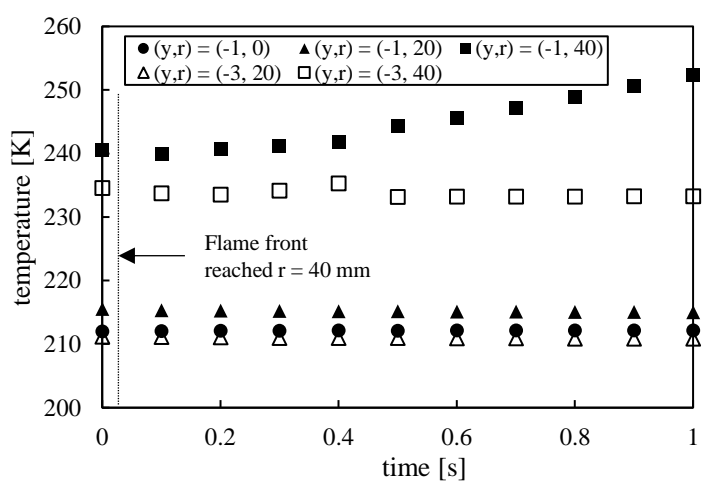

(b)

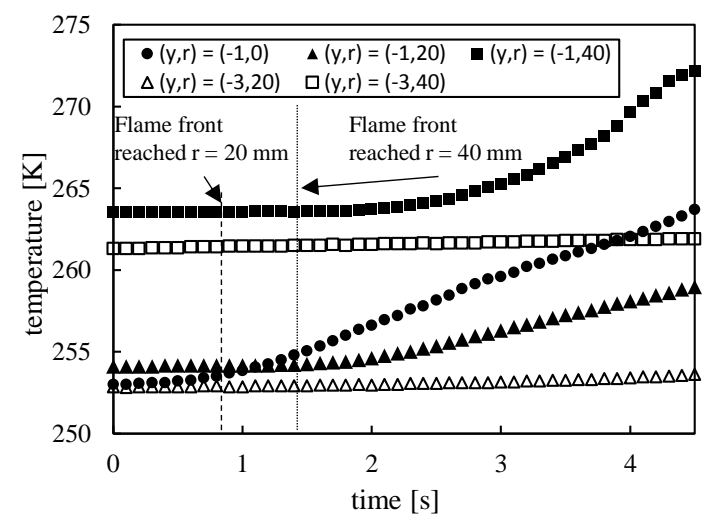

(d)

Figure 6 Temperature variations in the methane hydrate surface during the flame propagation: (a) $T_{\mathrm{s}, \mathrm{ig}}=173 \mathrm{~K}$; (b) $T_{\mathrm{s}, \mathrm{ig}}=213 \mathrm{~K}$; (c) $T_{\mathrm{s}, \mathrm{ig}}=233 \mathrm{~K}$; and (d) $T_{\mathrm{s}, \mathrm{ig}}=253 \mathrm{~K}$ 


\subsection{Flame propagation mechanism}

Low-speed flame propagation was observed at $T_{s, i g}=173$ and $253 \mathrm{~K}$, whereas high-speed flame propagation was observed at $T_{s, i g}=193$ and $213 \mathrm{~K}$. During low-speed flame propagation, the flame propagated by dissociating methane hydrate in front of the flame front mainly through the heat transfer from the flame front to the hydrate. The heat transfer was the main factor in flame propagation and the flame propagation velocity was as low as $10 \mathrm{~mm} / \mathrm{s}$. During high-speed flame propagation, the methane hydrate dissociated and methane spread over the methane hydrate and mixed with air before ignition. Thus, when the flame was ignited, it propagated through the methane-air mixture over the methane hydrate surface. Similar types of flame propagation were observed for a flame spreading in a forced convective laminar boundary layer flow (Maruyama et al. 2013).

At $T_{s, i g}=233 \mathrm{~K}$, the transition between flame propagation behavior was observed. After ignition, the flame started to propagate with a high propagation velocity, similar to those at $T_{s, i g}=193$ and $213 \mathrm{~K}$. When the flame reached around $r=$ $40 \mathrm{~mm}$, the flame propagation velocity decreased dramatically because ice formed over the methane hydrate, and the velocity was closer to that at $T_{s, i g}=173$ and $253 \mathrm{~K}$. The surface temperature was in the self-preservation range at $r=40$ $\mathrm{mm}$, and the methane ejection velocity was as low as for $T_{s, i g}=173 \mathrm{~K}$. Thus, the flame propagation velocity dropped sharply at around $r=40 \mathrm{~mm}$.

\subsection{Flame oscillation in low-speed flame propagation}

During the low-speed flame propagation, the flame front and the flame width at $y=20 \mathrm{~mm}$ oscillated periodically (Figure 7). The frequency of both the oscillations was about $10 \mathrm{~Hz}$, corresponding to the motion of the flame wrinkling induced by the Kelvin-Helmholtz instability, which occurs at the boundary of hot and cold gas under the influence of buoyancy (Ueda and Cheng 1991). Thus, the oscillation of the flame propagation was caused by buoyancy, and thus was observed in only a natural convective flow field. In the case of high-speed flame propagation, the flame propagation completed in around $0.04 \mathrm{~s}$ which was faster than the period of flame oscillation due to the Kelvin-Helmholtz instability $0.1 \mathrm{~s}$. As a result, no oscillation of the flame front was observed.

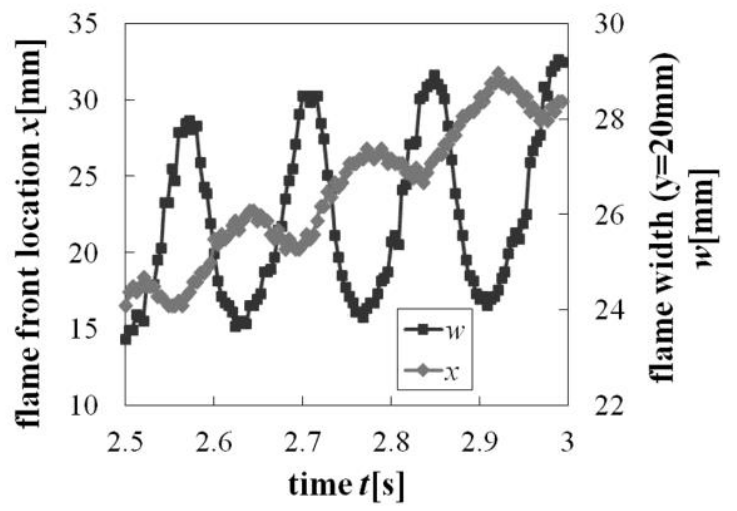

Figure 7 Flame oscillation during low-velocity flame propagation $\left(T_{\mathrm{s}, \mathrm{ig}}=173 \mathrm{~K}\right) ; x$, flame front location; $w$, flame width at $y=20 \mathrm{~mm}$

\section{Conclusions}

Flame propagation over an axisymmetric methane hydrate surface under natural convective flow conditions was investigated experimentally. The initial surface temperature increased with the radial distance from the centerline due to the heat transfer from the side wall of container. When the centerline surface temperature at ignition, $T_{s, i g}$, was lower than the dissociation temperature of the methane hydrate, the flame propagated slowly, dissociating the hydrate in front of the flame front by heating the hydrate surface. As $T_{s, i g}$ increased and exceeded the dissociation temperature of the methane hydrate, the flame propagated faster through the methane-air mixture formed from the methane gas ejected from the dissociated hydrate. As $T_{s, i g}$ increased, the flame propagated fast until the flame front reached the region under self- 
preservation conditions, whereupon the flame propagation velocity decreased dramatically because ice formed over the methane hydrate, decreasing the methane gas ejection. As $T_{s, i g}$ increased further, and $T_{s, i g}$ was in the self-preservation range, the flame propagated slowly, as in the case of $T_{s, i g}=173 \mathrm{~K}$, Interestingly, the slow flame propagation in the natural convection flow field oscillated because of Kelvin-Helmholtz instability.

\section{References}

Chen, X. Li, X. Chen, Z. Zhang, Y. Yan, K. and Lv, Q., Experimental Investigation into the Combustion Characteristics of Propane Hydrate in Porous Media, Energies, Vol.8 (2015), pp.1242-1255.

Gudmundsson, J. S. and Borrehaug, A., Frozen Hydrate for Transport of Natural Gas, Proceedings of the 2nd International Conference on Gas Hydrates (1996), pp.415-422.

Iwata, M. and Ueda, T., Combustion Behavior of a Combustible Clathrate Hydrate in a Laminar Boundary Layer over a Hydrate, Proceedings of the 4th International Conference on Gas Hydrates (2002), pp.1059-1062.

Javanmardi, J. Nasrifar, K. Najibi, S. H. and Moshfeghian, M., Economic evaluation of natural gas hydrate as an alternative for natural gas transportation. Applied Thermal Engineering, Vol.25 (2005), pp.1708-1723.

Kim, N. J. and Kim, C. B., Study on gas hydrates for the solid transportation of natural gas, KSME International Journal Vol.18, No.4, (2004), pp.699-708.

Kitamura, Y. Nakajo, K. and Ueda, T., Numerical calculation of a diffusion flame formed in the laminar boundary layer over methane-hydrate, Proceedings of the 4th International Conference on Gas Hydrate (2002), pp.1055-1058.

Klauda, J. B. and Sandler, S. I., Global Distribution of Methane Hydrate in Ocean Sediment, Energy Fuels, Vol.19, No.2, (2005), pp.459-470.

Maruyama, Y. Fuse, J. M. Yokomori, T. Ohmura, R. Watanabe, S. Iwasaki, T. Iwabuchi, W. and Ueda, T., Experimental investigation of flame spreading over pure methane hydrate in a laminar boundary layer, Proceedings of the Combustion Institute, Vol.34 (2013), pp.2131-2138.

Mori, Y. H., Recent advances in hydrate-based technologies for natural gas storage, Chinese Journal of Chemical Engineering, Vol.54 (2003), pp.1-17.

Nakamura, Y. Katsuki, R. Yokomori, T. Ohmura, R. Takahashi, M. Iwasaki, T. Uchida, K. and Ueda, T., Combustion Characteristics of Methane Hydrate in a Laminar Boundary Layer, Energy Fuels, Vol.23 (2009), pp.1445-1449.

Stern, L. A. Circone, S. Kirby, S. H. and Durham, W. B., Anomalous Preservation of Pure Methane Hydrate at 1 atm, Journal of Physical Chemistry B, Vol.105 (2001), pp.1756-1762.

Ueda, T. and Cheng, R. K., Interaction of Jet Diffusion Flamelets with Grid-generated Co-flow Turbulence, Combustion Science and Technology, Vol.80 (1991), pp.121-135. 